\title{
Tanto andar a los mandobles para terminar a los besuqueos acerca de la relegitimación de los políticos argentinos*
}

\author{
'Tanto andar a los mandobles \\ para terminar a los besuqueos' \\ on the re-legitimacy of Argentine politicians ${ }^{1}$
}

\author{
WALDO ANSALDI \\ Investigador del Consejo Nacional de Investigaciones Científicas y Técnicas \\ (CONICET), con sede en el Instituto de Estudios de América Latina y el Caribe, \\ Facultad de Ciencias Sociales de la Universidad de Buenos Aires. \\ Profesor titular de Historia Social Latinoameric ana y del Taller de \\ Sociología Histórica de América Latina, en la misma Facultad. \\ waldoansaldi@gmail.com
}

RESUMEN Desde el 10 de diciembre de 1983 hasta el momento de escribir estas líneas han trascurrido, en Argentina, veintitrés y medio años ininterrumpidos de vida democrática. Es la primera vez que ello ocurre en la historia del país, superando la primera experiencia de los años 1912-1916 a 1930. El articulo considera la crisis de representatividad de los partidos políticos y, más exactamente, la crisis de la legitimación de los políticos, tan duramente

\footnotetext{
Artigo recebido em 02/07/2007. Autor convidado.

(Este artículo expone resultados alcanzados en la investigación Nación, ciudadanía y derechos humanos en los países del MERCOSUR. Proyecto S 004, aprobado y financiado por la Secretaría de Ciencia y Técnica de la Universidad de Buenos Aires. Retoma, amplía, y en ocasiones rectifica, análisis ya expuestos).

1 Ver: ANSALDI, Waldo. Los náufragos no eligen puerto. Análisis de la situación argentina, 2000-2002. e-l@ tina. Revista electrónica de estudios latinoamericanos, Año I, No 1, Buenos Aires, octubre-diciembre 2002, p. 29-37, en http: //www.iigg.fsoc.uba.ar/elatina.htm; ANSALDI, Waldo. Argentina, una crisis sin fin. Gramsci e o Brasil, en www. gramsci.org.br/textos/politica, 2003; ANSALDI, Waldo. Argentina: la dilución de posibles salidas políticas. Asociación de Historia Actual. Boletín no 6, Cádiz, p.2-3, primavera 2003; ANSALDI, Waldo. El faro del fin del mundo. La crisis argentina de 2001 o cómo navegar entre el riesgo y la seguridad. http: //www.catedras.fsoc.uba.ar/udishal, 2003.
} 
cuestionados cuando la movilización de los días 19 y 20 de diciembre de 2001 (con la consigna: "que se vayan todos"). La crisis de 2001 hoy muestra un viraje, en particular, porque los políticos han sido relegitimados por la misma ciudadanía que los hizo objeto de escarnio. En el breve lapso entre abril y setiembre de 2003, el escenario político argentino experimentó una rápida, notable y (para muchos) inesperada transformación. Contra las radicales consignas del caliente verano 2001-2002, son demasiados los casos de quienes han recuperado, por el voto popular, su continuidad en cargos políticos.

Palabras-clave políticos, crisis de representatividad, Argentina

ABSTRACT Since December, 10, 1983, twenty-three and a half years have passed of uninterrupted democracy in Argentina. This is the first time in the history of the country that such a thing happens, going beyond the first experience of the years 1912-1926 to 1930. This article considers the crisis of representativity of political parties and, more exactly, the crisis of legitimacy of politicians, so hard questioned during the mobilization of December 19 and 20, 2001 (with the motto: "Let them all go away"). The crisis of 2001 is now showing a turning point, particularly because politicians have been relegitimated by the same citizenship that made them object of insult. In the short lapse between April and September 2003, the Argentine political scene experienced a remarkable and rapid and (for many people) unexpected transformation. Against the radicals mottos of the hot summer 2001-2002, many politicians have regained, through popular vote, their continuity in public service.

Key words politicians, crisis of representativity, Argentine

\section{Presentación}

Desde el 10 de diciembre de 1983 hasta el momento de escribir estas líneas han trascurrido, en Argentina, veintitrés y medio años ininterrumpidos de vida democrática. Es la primera vez que ello ocurre en la historia del país, superando la primera experiencia de los años 1912-1916 a 1930. No es un dato menor para entender la historia del tiempo presente de esta sociedad.

Entre las varias líneas de abordaje del período, aquí he de considerar, principalmente, la crisis de representatividad de los partidos políticos y, para decirlo con más exactitud, la de la legitimación de los políticos, tan duramente cuestionados cuando las movilizaciones del verano 2001-2002. Si bien el artículo hace algunas referencias al período iniciado en 1983, el énfasis del análisis está puesto en la coyuntura de la crisis de 2001, la cual hoy muestra, al menos en apariencia, un viraje, en particular porque, contra 
muchos pronósticos, los políticos han sido relegitimados por la misma ciudadanía que los hizo objeto de escarnio. En muchos casos, no sólo políticos en abstracto, sino políticos como personas individualmente identificables, reelectos por el voto popular.

\section{El retorno de los políticos}

El 1 de julio de 1982, con la dictadura institucional de las Fuerzas Armadas ya en retirada, se dispuso la derogación de la ley 21.233, oportunamente sancionada para reprimir las actividades políticas. El 27 de agosto, el último dictador, el general Reynaldo Bignone, anunció la promulgación de la Ley Orgánica de los Partidos Políticos, el instrumento pergeñado para reorganizarlos, paso previo a la convocatoria a elecciones generales para elegir a las nuevas autoridades legislativas y ejecutivas del país. Formalmente, la ley implicaba refundar los partidos preexistentes, o fundar nuevos, mas lo cierto es que la mayoría de los partidos, en particular los históricos, no había desaparecido por completo durante la dictadura. Como bien ha mostrado César Tcach, a lo largo de los años 1976-1983, los partidos subsistieron, sobre todo, mediante "la práctica política de sus equipos dirigentes, hecha de denuncias y también de silencios, pero cuya continuidad fue un dato insoslayable para estimular la renovada fe en los partidos que vivió la sociedad argentina a partir de 1982". ${ }^{2}$ Marcos Novaro y Vicente Palermo ${ }^{3}$ coinciden en la apreciación: en buena medida, la suspensión hizo posible la permanencia de los dirigentes en sus cargos, al tiempo que "los partidos que no habían sido prohibidos mantuvieron una cierta actividad en los años del terror, aunque reservada y acotada".

La nueva norma obligaba a un proceso de afiliación-reafiliación, obligatoria para todos cuantos quisiesen participar del futuro proceso de elecciones internas para elegir autoridades y candidatos. El final de la campaña arrojó un resultado espectacular, que muchos leyeron, sin yerro, como un inequívoco plebiscito informal contra la dictadura y a favor de la democracia: alrededor de un tercio de las mujeres y hombres que constituían el padrón electoral del país (unas 14.000.000 de personas) se afilió a algún partido político. Como era previsible, los dos partidos populares, el J usticialista y la Unión Cívica Radical, lograron los niveles más altos de afiliación: 3.500.000 y 1.400 .000 , respectivamente.

El 30 de octubre de 1983, las elecciones que consagraron Presidente de la República al dr. Raúl Alfonsín ratificaron el alto grado de participación

2 TCACH, César. Partidos políticos y dictadura militar en Argentina (1976-1983). In: DUTRÉNIT, Silvia (cord.); ANSALDI, Waldo; CAETANO, Gerardo e TCACH, César. Diversidad partidaria y dic taduras: Argentina, Brasil y Uruguay. México DF: Instituto de Investigaciones dr. José María Luis Mora, 1996, p.26.

3 NOVARO, Marcos e PALERMO, Vicente. La dictadura militar (1976-1983). Buenos Aires: Editorial Piados, 2003, p.513. 
ciudadana en la decisión de elegir a sus representantes y gobernantes. Los resultados mostraron, entre otros varios puntos destacables, la exacerbada polarización entre los dos partidos mayoritarios: radicales y justicialistas sumaron el 92\% de los sufragios emitidos (52 + 40\%). También, la ínfima presencia del voto en blanco: apenas el $2 \%$ (casi 290.000 votos), guarismo que, empero, significaba el cuarto lugar en orden de importancia cuantitativa. La ciudadanía argentina ratificaba, así, su rechazo a la dictadura. En medio de euforias, desconciertos y amarguras, Guillermo Estévez Boero, el candidato del Partido Socialista Popular, de paupérrimo desempeño, acertó, sin embargo, en la explicación: "el mayor porcentaje de electores rechazó al régimen militar imperante en el país que impuso el plan de [el ex ministro de Economía de la dictadura, José] Martínez de Hoz". Y añadió, tratando de justificar los magros resultados de su partido: "la polarización operada no es representativa del mosaico político, sino que es la consecuencia de la falta de actividad política y de las características que se le dio a la campaña electoral". ${ }^{4}$ Si la explicación es discutible, en cambio es un acierto la aseveración acerca de la real representatividad de los partidos.

En verdad, lo significativo del, para muchos inesperado, triunfo de Alfonsín estuvo en su capacidad de infundir en el electorado la convicción de ser un candidato que no transaría con los militares en materia de derechos humanos y de componendas políticas. La mayoría de la ciudadanía entendió que él garantizaba mejor que nadie la posibilidad de instaurar la democracia sin concesiones a los militares. Alfonsín tuvo un gran acierto -si se lo juzga en términos de eficacia propagandística- al enfatizar que la democracia era la panacea para alimentarse, educarse y curarse. Pero conceptualmente introdujo, en una sociedad con pobre cultura democrática, un serio error, al asignar a la democracia objetivos y funciones que no les son propias o distintivas. Para muchos sectores, más atentos a la satisfacción de sus legítimas necesidades económicas que a los valores políticos democráticos y ciudadanos, el fracaso del gobierno radical en materia de trabajo (sobre todo, pero también en educación y salud) era también -y quizás sobre todo- el fracaso de la democracia.

Ahora bien, el retorno de los políticos y los partidos no puede verse como recuperación veloz de representatividad. Novaro y Palermo ${ }^{5}$ tienen razón cuando argumentan que "no es que los partidos no hubieran sido 'representativos' en los años previos", ni que su renacer fuese "una reedición de anteriores experiencias". La masiva y

En diario La Nación, Buenos Aires, 31 de octubre de 1983. (itálicas mías)

5 NOVARO, Marcos e PALERMO, Vicente. La dictadura militar (1976-1983). Buenos Aires: Editorial Piados, 2003, p.514-515. 
activa presencia de los ciudadanos en la reorganización partidaria en verdad expresaba tendencias simultáneas contradictorias, como una recomposición de los vínculos de pertenencia con ciertas fuerzas políticas, principalmente el radicalismo y el peronismo, y una relación más ambigua y condicionada con las organizaciones corporativas y el Estado (...). Si los partidos pudieron canalizar ese sentimiento colectivo, fue porque actuaron a la vista del público, ahora más que nunca, como expresión de la sociedad, a distancia del aparato del Estado. Así, en oposición al Estado autoritario, la dimensión más novedosa que trajo esta transición -en clave liberal republicana y la valorización del pluralismo políticoconvertía a los partidos en los destinatarios lógicos de la atención, las expectativas y la participación. (itálicas mías)

Va de suyo que los partidos reorganizados, e incluso los creados, en 1982-1983 no implicaron nada nuevo, en tanto tales, excepto el liderazgo de Alfonsín. No obstante, lo que ocurrió entonces tiene un significado posiblemente decisivo. Como bien ha indicado Tcach, ${ }^{6}$ fue un momento de inflexión, de efectiva ruptura con la tradición y la historia: la "politización golpista de los militares y [la] militarización de la política partidaria" se convirtieron en datos del pasado. Apareció, también, "una nueva dinámica interpartidaria sustentada en el compromiso antes que en la negación del adversario"?

César Tcach no yerra cuando pone como ejemplos de la nueva dinámica interpartidaria "la unidad de acción contra el golpismo militar durante la gestión de Alfonsín y la reforma constitucional de 1994". Sin embargo, al mismo tiempo, estos dos hechos tuvieron un efecto negativo: dejaron paso -sobre todo por el acuerdo radical-peronista para reformar la Constitución nacional (el llamado Pacto de Olivos, entre Menem y Alfonsín)- a la política a puertas cerradas, lejos de "la vista del público". Buena parte del descrédito de los políticos argentinos encuentra aquí un episodio relevante, no aislado sino un eslabón más de la cadena.

La década de 1990, signada por todas las taras asignadas al menemismo, exacerbó el descrédito de los partidos y los políticos y puso en cuestión la representatividad de unos y otros. En particular, los políticos y el funcionamiento de la política quedaron asociados con la corrupción. El clímax, se sabe, se alcanzó con la crisis iniciada a fines de 2001.

6 TCACH, César. Partidos políticos y dictadura militar en Argentina (1976-1983). In: DUTRÉNIT, Silvia (cord.); ANSALDI, Waldo; CAETANO, Gerardo e TCACH, César. Diversidad partidaria y dictaduras, p.86-87.

7 Comparto esta apreciación y le asigno al hecho una importancia decisiva, que no puedo tratar aquí. Diré tan sólo que, según mi hipótesis, la cultura política argentina se constituyó, desde el mismo momento de la ruptura de la situación colonial, en 1810, mediante la primacía de la lógica de la guerra - el otro como enemigo, al que, en el límite, hay que matar - sobre la lógica de la política - el otro como adversario -, ocluyendo o haciendo muy difícil y débil la constitución de una arena donde procesar las diferencias. 


\section{Odisea 2002}

La crisis argentina fue triple: económica (iniciada en 1998), social y política. Si bien las movilizaciones populares de los días 19 y 20 de diciembre de 2001 suelen tomarse como símbolo de la dimensión política de la crisis, sus comienzos visibles se sitúan en la renuncia del vicepresidente Carlos Chacho Álvarez, el 5 de octubre de 2000, y se hizo ya patente con los resultados electorales del 14 de octubre de 2001. No obstante, un análisis cuidadoso podría probar que ella empezó a incubarse en el momento mismo en que la Alianza decidió llevar como candidato a presidente a Fernando De la Rúa, un político conservador, mediocre y con antecedentes de gestión no muy felices. Esa candidatura pronosticaba un resultado negativo. Tal vez, incluso, la formación de la misma Alianza -al menos para los sectores predominantes, en el interior de ella, en términos cuantitativos y de dirección, esto es, el radicalismo afín a De la Rúa- conllevaba ese sino. La unión por el espanto (el menemismo) fue, así, más fuerte y decisiva que el programa (combatir al modelo neoliberal).

El 19 y el 20 de diciembre de 2001, la política se trasladó de los cenáculos a las calles. La política recuperó su acepción etimológica, lo cual es un dato significativo de la crisis. Una porción considerable de sectores sociales urbanos ganó las calles, es decir, la polis, y planteó, con avances y retrocesos, la posibilidad de recuperar y asumir la preocupación por la res pública. En momentos de crisis, los símbolos se tornan ilustrativos. Mientras la sociedad llevaba la política a las calles, los políticos profesionales -comenzando por los legisladores- la encerraban entre vallas, o sea, rejas. ${ }^{8}$

Cinco y medio años después de la caída estrepitosa del gobierno de la Alianza -la cual incluyó una treintena de muertos- lo viejo no ha terminado de morir, lo nuevo no ha terminado de nacer. Incluso, buena parte de lo viejo ha resucitado. Los ciudadanos siguen descreyendo de las dirigencias, no han encontrado el rumbo, ni la estrategia ni los instrumentos para solucionar la crisis. La burguesía cuenta con mejores chances y no vacila en emplearlas. Parte de la clase media ha recuperado un cierto grado de confianza y expectativas favorables, mientras otra vive todavía una situación de desorientación que no termina de procesar, escindida entre la búsqueda de nuevos caminos y la ahora diluida - por diferentes razones, tanto internas como externas -"salida por Ezeiza", fuerte en 2002. ${ }^{9}$ Secto-

8 Ello ya fue pasible de advertir el día en que la Asamblea Legislativa se reunió para tratar la renuncia del efímero presidente Adolfo Rodríguez Saá y designar al senador Eduardo Duhalde. El alto cuerpo sesionó dentro del edificio del Congreso rodeado de un vallado situado a 200 metros. Posteriormente, y hasta hoy, las vallas liberaron ese espacio, pero siguen cerrando la casa de las leyes, incluyendo no sólo el edificio principal sino también el anexo. Lo mismo ocurre con la Casa Rosada, la sede del Poder Ejecutivo.

9 Ezeiza es el aeropuerto internacional de la ciudad de Buenos Aires, el principal punto de salida al exterior que tiene el país. En el lenguaje popular, la alusión a que la "salida" es Ezeiza significa que no hay mejor opción que abandonar el país y tentar un mejor destino fuera de él. 
res de productores rurales, de agroindustriales y algunos otros industriales urbanos experimentan una sustancial mejoría y alientan la posibilidad de ampliarla, aunque los pequeños y medianos chocan con las dificultades para acceder a créditos.

En el plano social y político, la crisis se encuentra alejada del paroxismo de noviembre 2001 a marzo 2002, y algunos indicadores muestran que la situación ha mejorado para la mayoría de la población, pero no tanto como podría permitirlo el formidable y sostenido crecimiento de la economía desde 2003. Así, por caso, la desocupación descendió, en el primer trimestre de 2007, a 9,8\%, por debajo del 11,4\% de igual período de 2006 (en esos doce meses la economía creció 8,0\%), según el Instituto Nacional de Estadísticas y Censos (INDEC). ${ }^{10}$ La cuestión de la pobreza constituye un aspecto clave de la crisis social y su disminución -ya no su erradicación total - a los niveles históricos será una tarea ímproba, en caso de librarse un efectivo combate contra ella. También aquí la caída ha sido notable: en cinco años pasó del 57 al 27\% (si bien hay quienes sostienen que esta cifra es, en rigor, de casi 33\%).

\section{Argentina: los índices y la cuestión social}

En cinco años, la Argentina ha logrado bajar la pobreza del 54 al 27\% y el desempleo del 22 al 9\%. Es un logro indiscutible, y se corresponde con cinco años consecutivos de un fuerte crecimiento de la economía. Sin embargo, esta mejora tiene una contracara que es necesario asumir.

En primer lugar, aunque parezca un detalle, cuando se modifican índices del INDEC no sólo se alteran datos económicos -como la tasa de inflación-, sino que también se están modificando los datos sociales. Es que siendo el precio de los alimentos el indicador más relevante para determinar los niveles de pobreza e indigencia, éstos aparecen como inferiores a los reales. Posiblemente, sin estas alteraciones el índice de pobreza en la Argentina no sería del $27 \%$, sino aproximadamente del 33\%.

La cuestión se agrava en el caso de los niños. En materia de educación, la gran mayoría de los niños pobres concurre a la escuela pública. Una ley de 2002 establece un mínimo obligatorio de 180 días de clases, que es bajo en términos internacionales. Sin embargo, desde la vigencia de esta norma, por tres años consecutivos, tres de cada cuatro niños que se educan en la escuela pública no han llegado a dicho mínimo, ya que en grandes distritos -como Buenos Aires, Córdoba y Santa Fe-, en más de una oportunidad no se ha cumplido con lo estipulado en la mencionada ley, y es posible que

10 Ese índice se logra incluyendo como ocupados a los beneficiarios de los planes asistencialistas. Si, como en rigor debe procederse, se los excluye de tal condición, la desocupación asciende a alrededor del 12\%, que no deja de ser un indicador de un fuerte descenso (con la crisis llegó al 22 por ciento). 
ello vuelva a suceder este año, dada la dimensión que está adquiriendo el conflicto docente. Además, más del $90 \%$ de la escuela pública tiene escolaridad de sólo cuatro horas, con lo cual las horas totales que se concurre a ella son muy pocas. Queda así claro que, a mayor pobreza, peor calidad de educación.

En cuanto a la salud, la casi totalidad de los padres de los niños que viven en la pobreza no tienen un trabajo formal, con lo cual carecen de la cobertura de salud de las obras sociales o de las prepagas. Es decir, tienen la peor calidad de salud, reducida a un hospital público que no pasa por el mejor momento.

Pero a este cuadro hay que agregar que, según el Sedronar, el organismo oficial encargado de la lucha contra la droga, entre 2001 y 2006 el incremento en el consumo de drogas en estudiantes de la franja etaria de los 13 a los 17 años ha sido del 67\% en marihuana, 120\% en cocaína, $200 \%$ en paco y $380 \%$ en pegamento. Las dos últimas son las drogas que consumen los chicos que viven bajo el nivel de pobreza, por su bajo costo. Se puede conjeturar que estos porcentajes pueden ser mayores aún en los jóvenes no escolarizados.

El análisis en conjunto del nivel de pobreza en los menores de 14 años - I a baja calidad de la educación y la salud pública que tienen, y el fenomenal aumento del consumo de las drogas más baratas en los jóvenesestá diciendo que, pese a la recuperación económica, la reconstitución del poder político y la mejora en los indicadores sociales, se está gestando un segmento de pobreza estructural o permanente, que afectará en el largo plazo a un tercio de la población, más allá de las mejoras estadísticas.

La falta de personal calificado que enfrentan hoy muchas empresas, el aumento de los delitos y la mayor violencia en la comisión de éstos, y el porcentaje de analfabetos funcionales -los que han tenido pocos años de primaria y han perdido las nociones de lectura y escritura por la falta de ejercicio- son algunos de los fenómenos que dan cuenta de la gestación de esta pobreza estructural.

La pobreza y la indigencia crecieron pese a la implementación masiva de la asistencia estatal mediante los Planes Jefes y Jefas de Hogar -en teoría, un subsidio universal otorgable a cualquier jefe de familia (hombre o mujer) de todo el país con hijos a cargo, desocupado y que no reciba otro beneficio social. Llegaron a concederse a unos 2 millones de hombres y mujeres considerados jefes de hogares. Si bien el subsidio era monetariamente bajo -alcanzaba apenas para cubrir menos de la mitad de una canasta básica familiar de alimentos-, permitió morigerar la dureza de la condición de vida de los recipiendarios. Sin esos planes, la pobreza y la indigencia hubiesen sido aún mayores. Empero, la importancia mayor de estos planes asistencialistas radica en su formidable capacidad de contención de la conflictividad social. 


\section{Mandobles: la profundización de la crisis de representatividad de los partidos políticos}

Las crisis suelen ser ocasiones propicias para la aparición de nuevas formas de representación, organización y acción. En la larga crisis actual, sectores de la sociedad argentina -en particular los más afectados - han generado algunas bien interesantes, tales como los piqueteros y las asambleas barriales.

Los primeros piquetes aparecieron en junio de 1996, protagonizados por trabajadores petroleros de Cutral-Có, a los que se sumaron luego, en 1997, los de Tartagal, desocupados tras el proceso de privatización de Yacimientos Petrolíferos Fiscales (YPF, empresa emblemática), adoptando la modalidad del corte de rutas, al estilo de los campesinos bolivianos. Ambos fueron inicialmente desactivados por el gobierno de Menem, apelando al otorgamiento de planes de asistencia para desocupados. Empero, poco después, empezaron en el Gran Buenos Aires. Su expansión cuantitativa, como forma de lucha, fue muy rápida. En los inicios, sus demandas se centraban, casi exclusivamente, en materia de alimentación, salud, vivienda, educación y, de manera central, como es obvio, trabajo.

En los piquetes participan tanto hombres como mujeres, unos y otras en una amplia banda etaria. En su organización y modus operandi es posible apreciar el pasado obrero. Sólo la experiencia de las luchas sindicales puede dotar de instrumentos de las características de los empleados, incluyendo la apelación a la violencia. Política e ideológicamente constituyen un mosaico de posiciones, a menudo con importantes divergencias, aunque todos se reconocen como parte del campo popular, una expresión ambigua que sirve para potenciar lo que los une y postergar el análisis de las diferencias. Si bien las organizaciones piqueteras no responden orgánicamente a partidos políticos, su división en varias tiene algunos correlatos en posiciones políticas, especialmente en el caso de los dirigentes, mucho más que en el de las bases, en general sin formación ni experiencia política previa. ${ }^{11}$

11 Así, por ejemplo, el Bloque Piquetero, constituido por el Polo Obrero, el Movimiento Teresa Rodríguez y otras tres agrupaciones menores, reúne un significativo número de trotskistas (especialmente del Partido Obrero) y antiguos militantes comunistas, sin excluir a quienes carecen de pertenencia política, y no excluye la posibilidad de constituir un frente y participar de procesos electorales. A su vez, en el Movimiento de Trabajadores Desocupados Aníbal Verón se encuentran "guevaristas", "peronistas rebeldes", militantes de organizaciones defensoras de derechos humanos y de base de la Iglesia. Su posición es inequívocamente antisistema, negándose a participar de las elecciones y apostando, a largo plazo, a la revolución popular (a diferencia del Polo Obrero, que sostiene que ella comenzó con la caída del presidente Fernando De la Rúa). En la mayor organización piquetera, al menos por número de miembros y extensión geográfica, la formada por la Federación Tierra y Vivienda y por la Corriente Clasista y Combativa, hay hombres con una bien variable experiencia política, pasada y/o presente, desde peronistas, viejos sindicalistas y militantes laicos de la Iglesia hasta comunistas revolucionarios (que en los años 1960-1970 eran "pro chinos"). Esta organización está ligada a la Central Argentina de Trabajadores, una experiencia innovadora en las luchas sindicales. No desdeña la lucha electoral y algunos de sus dirigentes ocupan cargos políticos. Procura una política de alianza con la clase media y con los sindicatos combativos y es más proclive a la negociación que al enfrentamiento directo con la policía. 
Las organizaciones piqueteras generaron un nuevo tejido social, a partir de originales formas de acción en los barrios, las cuales abarcan desde huertas vecinales hasta comedores y centros de salud comunitarios. Empero, el potencial disruptivo se ha visto ocluido por la entrada en la lógica perversa de funcionamiento del sistema político tradicional. El Estado destina una importante suma anual de dinero para atender los Planes Jefes y Jefas de Hogar y éstos se han convertido, adicionalmente a su objetivo específico, en una fuente de financiamiento de dichas organizaciones. Ellas rompieron el antiguo monopolio del reparto de la ayuda social, que compartían caudillos políticos y sindicales, pero no con la práctica de negociar con el Estado (en los niveles nacional, provincial y municipal) y entre ellas mismas, el quantum del reparto. De ese modo, terminó imponiéndose la lógica clientelar, propia de este tipo de planes, a la cual no escapan las organizaciones más contestatarias. Más aún, han sido capturadas -o se sumergieron, también ellas- en la histórica primacía de la lógica corporativa, tan típica del sistema político argentino, según una hipótesis que he planteado hace ya más de una década. Por otra parte, la frecuencia de sus movilizaciones callejeras le ha enajenado el anterior apoyo de buena parte de la clase media, especialmente en la Capital Federal. Adicionalmente, el gobierno del presidente Kirchner ha realizado un notorio trabajo de captación de dirigentes piqueteros (transformismo molecular, si se quiere).

La crisis generó otra gran novedad, las asambleas vecinales o barriales, constituidas en algunas de las principales ciudades del país, aunque mayoritarias en la de Buenos Aires. En ellas, miles de vecinos se reunieron espontáneamente para tratar de dar respuesta a una de las dos caras -a veces, a ambas- de la tensión que generaron con su sola existencia y acción: construir nuevas formas de instituir lo público-político, superando la institucionalidad estatal existente y la mediación partidaria, en un plano más macrosociológico, o bien ceñirse a la atención del espacio barrial, con sus diversas necesidades, en una plano más microsociológico. Así, creación de comedores populares, realización de acciones solidarias con cartoneros y convergentes con piqueteros, otras manifestaciones colectivas, amén de encuentros interasambleas dieron cuenta de la potencialidad de esta nueva forma de participación desde abajo. Las asambleas barriales fueron -siguen siendo, pese a su casi agostamiento- una formidable experiencia de recuperación de la política, del espacio público y de la participación activa. Ellas devolvieron a la política su significado etimológico. La derecha y la izquierda realmente existente las vieron como expresión argentina de los antiguos soviets y actuaron en consonancia: la primera, para terminar con ellas; ${ }^{12}$ la segunda, proponiéndose como vanguardia de las mismas y

12 El tradicional diario de derecha La Nación encontraba en las asambleas un embrión de soviets y los descalificaba por ser mecanismos informales de toma de decisiones y un peligro para la democracia representativa. Véase, por 
haciendo todo lo posible por cooptarlas, provocando una fuerte corriente de vecinos desertores, es decir, también para terminar con ellas. De hecho, la izquierda realmente existente, con su manía vanguardista y su estrategia de cooptación, es altamente responsable del fracaso de esta novedosa y rupturista experiencia. Por acción de una y otra, pero también por incapacidad de pasar a una instancia superior de organización y acción, las asambleas barriales, más allá de algunas prácticas innovadoras y exitosas, entraron en franco declive como espacio no sólo renovador de la práctica política, sino como embrión de una profundización de la democracia.

Ahora bien: entre diciembre de 2001 y diciembre de 2003 -dos largos años- se constata el pasaje de una situación cuasi insurreccional a unas elecciones presidenciales con alta participación ciudadana y una fase de estabilización institucional, dentro de la cual es factible apreciar que los cinco principales candidatos (provenientes todos ellos de los dos partidos tradicionales, el radicalismo y el justicialismo) sumaron casi el $95 \%$ de los votos, a modo de mentís rotundo a la movilizadoras consignas del verano 2002, Que se vayan todos, que no quede ni uno solo y Piquetes, cacerolas I la lucha es una sola. Se trata de un viraje más que significativo.

Durante ese tiempo, institucionalmente se produjeron los locos diez últimos días de diciembre de 2001: renuncia del presidente De la Rúa, designación de Ramón Puerta, presidente del Senado, como efímero Presidente provisional, reemplazado por Adolfo Rodríguez Saá, a quien la Asamblea Legislativa nombró, sorpresivamente, con la intención de una pronta convocatoria a elecciones. Empero, las reales o supuestas intenciones del nuevo mandatario de ejercer el cargo hasta completar el período iniciado por De la Rúa (es decir, hasta el 10 de diciembre de 2003), generaron una fuerte oposición dentro del propio Partido Justicialista y, por extensión, una situación de debilidad que le llevaron, tras apenas una semana en el cargo, a presentar su renuncia -con sabor a destitución-, y a su reemplazo, también interinamente, por Eduardo Caamaño (presidente de la Cámara de Diputados) y, finalmente, al nombramiento del senador Eduardo Duhalde, otra vez por decisión del Congreso en pleno, con mandato hasta el 10 de diciembre de 2003. Puerta, Rodríguez Saá, Caamaño y Duhalde eran miembros del Partido Justicialista.

En su efímera gestión, Rodríguez Saá declaró, con los aplausos de los legisladores, la suspensión del pago de la deuda externa (default), aunque, según alguna información, ella no se hizo efectiva -todo lo contrario, pues se habrían realizado pagos- durante aquélla. A esta medida le siguieron, ya bajo el gobierno de Duhalde, la devaluación del peso -que llevó a una

ejemplo, el editorial "Asambleas barriales" de la edición del 14 de febrero de 2002. Por cierto -y obviamente-, el diario ha silenciado y silencia el poder informal del capital financiero y de los organismos internacionales como el Fondo Monetario Internacional. 
fuerte suba de los precios y a un mayor deterioro del salario real-, un cierto desabastecimiento de productos esenciales, y el descalabro de actividades civiles y comerciales reguladas jurídicamente (contratos, deudas, depósitos dolarizados), amén de una formidable ruptura de las reglas de juego institucional o, si se prefiere, un desquicio social, económico y político. ${ }^{13}$

Para el gobierno de Duhalde se trató, en primer lugar, de restablecer el orden, evitar la continuidad de la violencia y construir un nuevo -tal vez más que reconstruir- marco regulador del funcionamiento del sistema bancario-financiero y comercial. Como ya había advertido Eduardo Basualdo antes de la crisis desatada en noviembre-diciembre de 2001, en el fondo, la confrontación era entre dos grandes fracciones burguesas: una, la dominante hasta la crisis, conformada por grupos económicos locales y algunos extranjeros, con base económica en colocaciones financieras en el exterior, y la otra, "posicionada en activos fijos con obligaciones dolarizadas, el sector financiero y los diferentes inversores extranjeros que adquirieron empresas y paquetes accionarios durante los años previos". ${ }^{14}$

Lo que el gobierno de Duhalde hizo fue reasignar recursos, de manera tal que los grandes beneficiarios resultaron los bancos (a los cuales el Estado compensó económicamente por las pérdidas generadas por la pesificación), los grupos económicos endeudados en dólares (beneficiados por la pesificación de sus deudas), los grandes propietarios y empresas rurales productores de materias primas y, por extensión, los consorcios exportadores, en buena medida transnacionalizados, para quienes un dólar alto es una fuente de ganancias (lo que ha llevado a algunos grupos agroindustrales a vender en el mercado local a precios del mercado internacional). Políticamente, ambas fracciones fueron definiéndose en torno a dos grandes posiciones: la integrada por los partidarios de la dolarización, la incorporación al ALCA y la intervención militar para reprimir el conflicto social, y la constituida por los partidarios de la devaluación y pesificación y, aunque no necesariamente por todos, el fortalecimiento del Mercosur.

Un tercer bloque de fuerzas tuvo posibilidades de constituirse como una alternativa popular con orientación de centro izquierda a izquierda y base social en el sindicalismo no burocrático y en los diferentes sujetos sociales partícipes de las luchas recientes. No obstante, careció de capacidad de convertir una posibilidad en una realización.

13 Aunque no siempre se lo tiene en cuenta, las crisis - especialmente las más agudas - son también crisis de derechos. En el caso argentino, la magnitud de la misma fue tal que afectó derechos civiles fundamentales de una economía y una sociedad capitalista, incluyendo el mismísimo derecho de propiedad privada, como en el caso de la confiscación de los depósitos bancarios.

14 BASUALDO, Eduardo. Sistema político y modelo de acumulación en la Argentina. Notas sobre el transformismo argentino durante la valorización financiera (1976-2001). Bernal: Universidad Nacional de Quilmes Ediciones, 2001, p.86-87. 
El acceso de Eduardo Duhalde a la presidencia, y su permanencia, fue factible, según el análisis del Colectivo Situaciones, ${ }^{15}$ por, al menos, tres razones: 1) la ruptura del pacto de dominación expresado por el menemismo, dentro del cual la hegemonía detentada por los capitalistas de las empresas privatizadas (extranjeros en o sin alianza con burgueses locales) y el sector financiero transnacional; 2) la solidez del justicialismo bonaerense, controlado por el propio Duhalde, con notable persistencia de su capacidad de penetración en los sectores sociales más pobres y con un nivel de organización capaz de controlar el conflicto social, en buena medida mediante redes clientelares, eficazmente utilizadas en la distribución de unos dos millones de planes sociales; 3) la capacidad de ese mismo justicialismo bonaerense para ofrecerse, ante la ruptura institucional, "como último garante de los restos del sistema polític 0 ". ${ }^{16}$ El principal aporte del gobierno de Duhalde a la salida de la crisis -sostiene el Colectivo Situaciones, y yo coincido - tuvo como mérito fundamental el "subsistir al juego de presiones cruzadas y, particularmente, a la amenaza constante de las cacerolas". ${ }^{17}$

El proceso de recomposición del sistema político se hizo más definido a partir del segundo semestre de 2002 y giró alrededor de tres aspectos: 1) la gestión del ministro de Economía, Roberto Lavagna, quien asumió el cargo el 27 de abril de ese año y la llevó adelante compatibilizando intereses; manteniendo el valor del dólar en un cambio alto (alrededor de los tres pesos), pero lejos de las estimaciones agoreras de economistas neoliberales que pronosticaban un cambio que iba de los 7 a los 10 pesos; logrando controlar la inflación, alejando el fantasma y el riesgo de la hiperinflación. Complementariamente, comenzó a producirse un crecimiento de los sectores económicos beneficiados, primero moderado, luego muy notable; 2) la distribución de los planes sociales fortaleció a los aparatos políticos y sus redes de clientelismo, permitiendo un importante control de las protestas y, por tanto, una cierta tranquilidad social; 3) el aumento de la represión de los conflictos y movilizaciones sociales, cuyo punto máximo fue la ejercida en Puente Pueyrredón, que une la ciudad de Buenos Aires con la de Avellaneda, el 26 de junio del 2002. En este operativo represivo fueron asesinados, por efectivos policiales, dos jóvenes piqueteros, Maximiliano Kosteki y Darío Santillán.

15 COLECTIVO SITUACIONES. Causas y azares (Dilemas del nuevo protagonismo social). Borradores de Investigación 4, fechado el 18 de mayo de 2003, distribuido por vía electrónica.

16 El Colectivo Situaciones es una experiencia original iniciada, en principio, por estudiantes de izquierda de la Facultad de Ciencias Sociales de la Universidad de Buenos Aires, trasladada luego a barrios de la Capital Federal y su conurbano y a provincias Se autodefine como un "grupo de investigación y pensamiento" que enfatiza el pensar sobre el saber. Trabajan en pos de una estructura de base, horizontal e independiente (autónoma). Ha realizado aportes muy novedosos para pensar la realidad argentina y latinoamericana de los últimos años. Véase http://www.situaciones.org/

17 Apenas asumida la presidencia, Duhalde sostuvo: "con asambleas no se puede gobernar". 
Por diferentes razones, Duhalde decidió anticipar la realización de las elecciones presidenciales y el traspaso del mando (del 10 de diciembre al 25 de mayo de 2003). En buena medida, tal decisión fue la respuesta al asesinato de los dos piqueteros. A juicio del Colectivo Situaciones, el adelanto de las fechas influyó sobre las tres tendencias a partir de las cuales el gobierno realizó un programa de reconstrucción mínima de institucionalidad: a) la consolidación, e incluso la baja, del precio del dólar, y la recuperación de una economía en descenso desde 1998; b) la apertura de un proceso electoral sobre los restos de los partidos políticos, en condiciones desfavorables para los candidatos, todos con muy bajos niveles de popularidad, y con un justicialismo (o peronismo) que, merced a una jugada de Duhalde, presentó no una sino tres candidaturas, una por cada línea interna; c) crecientes niveles de represión de las experiencias contestatarias, en particular de los piqueteros, con intervención de grupos armados sin uniforme, y la reactivación del aparato judicial para ordenar -antes de la primera vuelta electoral- el desalojo de fábricas ocupadas por sus trabajadores.

Un dato relevante, dentro de una coyuntura tan crítica, es el alto grado de adhesión a la democracia por parte de los argentinos de hoy, no exento de una paralela insatisfacción con los resultados alcanzados en ella.

La ruptura entre representantes y representados -a menudo centrada en la relación entre los partidos políticos y sus bases y votantes, pero también constatable en las principales organizaciones de representación de intereses, en particular los sindicatos obreros- no ha dejado de tornarse cada vez más profunda. La crisis terminó con el Frente País Solidario (FREPASO) -el último y, otra vez, frustrado intento de constituir un tercer gran partido-, que fue parte del gobierno de la Alianza, arrasado por los hechos de diciembre de 2001, y fracturó fuertemente a los dos grandes partidos tradicionales de masas, la Unión Cívica Radical (UCR) y el Partido J usticialista (PJ). Ninguno de ellos es ya lo que fueron históricamente y ambos aparecen cruzados por una línea que divide a los que se suman al proyecto que pretende construir el Presidente Kirchner y los que, por el contrario, son opositores.

La izquierda es muy poco relevante en términos electorales y sus propuestas tampoco ofrecen efectivas salidas a la crisis. Los resultados electorales lo demostraron con elocuencia. La expresión más innovadora, la de Autodeterminación y Libertad, encabezada por el diputado nacional Luis Zamora, decidió no participar de las elecciones por entender que hacerlo era convalidar un proceso al que consideraba ilegítimo. Se trata de una estrategia atendible, aunque es posible conjeturar que tácticamente fue un error, pues le privó de la posibilidad -siempre difícil para la izquierda argentina- de "tener tribuna" en los medios de comunicación masiva y de transmitir sus posiciones de manera más efectiva.

Durante la campaña electoral hubo ausencia de propuestas elaboradas y de debates de ideas. Los candidatos se instalaron como personajes de 
la televisión sin libreto. De hecho, su contacto con la ciudadanía fue casi exclusivamente virtual, a través de los medios de comunicación, en particular la televisión. Ninguno de ellos llegó a tener, en las encuestas previas, una intención de votos superior al 17 o 18\%. Los cuatro mejor posicionados - Menem, Kirchner, Rodríguez Saá y Carrió (no siempre en ese orden) oscilaban entre esa cifra máxima y una mínima de 13-14\%, variando los dos primeros lugares, según la empresa encuestadora y el momento. El llamado voto bronca, el voto en blanco y el impugnado y la abstención fueron opciones importantes inicialmente, aunque, significativamente, comenzaron a perder relevancia a medida que se acercaba la fecha de las elecciones, mostrando un viraje hacia la intención de participación activa y con voto positivo. En buena medida, ese viraje -un efectivo cambio de actitudcomenzó a hacerse visible cuando las encuestas comenzaron a mostrar un crecimiento en la intención de votos a favor de Menem. Tal perspectiva generó una fuerte preocupación por un efecto no previsto (ni querido por la mayoría) de la fragmentación del sistema político: el retorno de Menem al gobierno. Sin duda, tal perspectiva llevó a muchos a optar por alguno de los candidatos, más por posición anti Menem que por coincidencias o convicciones.

A la hora del conteo de los votos, Menem obtuvo 4.740 .907 votos (24,45\%); Kirchner, 4.312 .517 (22,24\%); López Murphy, 3.173 .475 (16,37\%); Rodríguez Saá, 2.735 .829 (14,11\%) y Carrió, 2.723 .574 (14,05\%). La UCR fue votada por sólo 453.360 ciudadanos (2,34\%). Izquierda Unida, constituida por el Partido Comunista y el Movimiento al Socialismo, de origen trotskista, sumó 332.863 sufragios $(1,72 \%)$ y un desvaído Partido Socialista -centro izquierda - logró apenas 217.385 votos (1,12\%). A su vez, el Partido Obrero, otra expresión del trotskismo argentino, y por tanto de la izquierda institucional o realmente existente, alcanzó 139.399 (0,72 \%). Otras fórmulas obtuvieron aún menos votos.

Los resultados obligaban a una segunda rueda electoral (ballotage) entre los dos candidatos más votados, la cual no se realizó por la deserción vergonzosa y dañina (para la institucionalización de la democracia) de la fórmula encabezada por Carlos Menem. Manifiestamente, la candidatura de Kirchner, en medida considerable desconocido por buena parte de la ciudadanía, fue impuesta y sostenida por el presidente Duhalde, quien logró controlar disciplinadamente al justicialismo de la provincia de Buenos Aires, responsable de una significativa proporción del quantum de votos obtenidos por el gobernador de la petrolera provincia de Santa Cruz. De hecho, Kirchner logró 1.910.516 votos en la primera provincia argentina. Esos guarismos representaban 25,72\% de los votos en Buenos Aires (contra $20,40 \%$ obtenido por Menem) y, más importante, $44 \%$ del total de su caudal electoral. Ello parecía colocar al nuevo presidente en la situación potencial 
si no de rehén al menos en la de fuerte condicionamiento por el poder del saliente, como bien se encargaron de repetir sus adversarios.

Para Kirchner, y para la institucionalización política y la propia democracia, la segunda vuelta era fundamental: podía capitalizar todo el voto antimenemista -las encuestas posteriores al 27 de abril le daban una intención de voto situada entre el 65 y el 70\%- y obtener un grado de legitimidad mayor. Convocada para tres semanas más tarde, el 18 de mayo, durante las primeras dos se produjo una masiva manifestación de apoyo a Kirchner por parte de dirigentes de casi todos los partidos, incluso de muchos dirigentes y votantes que en la primera vuelta habían optado por Menem. Éste renunció a participar en la segunda, acusando a Duhalde de organizar un fraude electoral y a Kirchner de ser un montonero. El hecho tuvo su importancia: las masivas concurrencias a las urnas y opción electoral positiva, en la primera vuelta, fueron claves para la recomposición de la institucionalidad representativa. La renuncia de Menem cortó el mecanismo institucional y privó al ganador del ballotage interruptus de ser elegido por un gran porcentaje del electorado. Pero esta situación se inscribió dentro del más amplio proceso de reconfiguración de todo el sistema político argentino, como quedó en claro con la posterior serie de elecciones para designar legisladores nacionales, Jefe de Gobierno de la Ciudad Autónoma de Buenos Aires y gobernadores de provincias, entre ellas las tres más importantes, Buenos Aires, Córdoba y Santa Fe, en las cuales triunfaron los candidatos justicialistas. ${ }^{18}$

Así, Néstor Kirchner se convirtió en el nuevo Presidente. Lo fue en una situación delicada, pues el escaso porcentaje de votos obtenidos en la primera vuelta le asignaba una baja legitimidad cuantitativa. A erosionarla aún más apostó la actitud de Menem. Empero, el presidente Kirchner mostró de inmediato una notable capacidad ejecutiva que le permitió suplir la débil legitimidad de origen por legitimidad de ejercicio: ha logrado un elevado grado de conformidad con sus medidas de gobierno, con valores que alcanzan, y a veces superan, el 70 y el $80 \%$ de los encuestados. Kirchner redefinió la agenda política y puso en primer plano cuestiones políticas y éticas devenidas centrales, incluso cuestión de Estado, como en el caso de la defensa de los derechos humanos y el enjuiciamiento de quienes los violen o hayan violado. También demostró capacidad de mando con la profunda renovación de las cúpulas de las Fuerzas Armadas, buscando no sólo dejar de lado a jefes presuntamente más cercanos a Menem, sino,

18 En Santa Fe, la mayoría de votos fue obtenida por el candidato del Partido Socialista, el hasta entonces exitoso intendente de la ciudad de Rosario, Hermes Binner; pero la aplicación de la ley de lemas (luego derogada) le escamoteó el triunfo en beneficio del PJ, que mediante la suma de todos sus candidatos superó los votos del socialista. Binner es nuevamente candidato a gobernador (elecciones 2007), otra vez con alta probabilidad de triunfo (sería el primero, a nivel provincial, del socialismo argentino). En Córdoba fue reelecto Juan Manuel de la Sota, frustrado delfín de Duhalde que coqueteó con Menem y devino en oportunista no opositor de Kirchner. 
sobre todo, contar con una conducción exenta de vinculaciones con la dictadura y la violación de los derechos humanos. ${ }^{19}$ En materia de seguridad comenzó un proceso depurador en la Policía Federal, si bien menos radical que el operado en Ejército, Marina y Aeronáutica. La embestida contra una Suprema Corte de Justicia, desprestigiada y funcional a los designios del menemismo, generó una renovación en la que primó el talento por sobre la obsecuencia. Asimismo, planteó un discurso de firmeza frente a las posiciones y pretensiones del Fondo Monetario Internacional y los acreedores internacionales, a menudo acompañado de acciones de igual tenor. Se posicionó muy bien en el plano de la política exterior, especialmente acordando posiciones con el Presidente de Brasil, Luiz Inácio Lula da Silva, e incluso con el de Venezuela, Hugo Chávez, entre ellas las relativas al relanzamiento, expansión y fortalecimiento del Mercosur. En cuanto a la relación con los Estados Unidos, una cuestión obviamente clave, el mensaje siempre ha sido claro: no habrá con ellos las "relaciones carnales" practicadas por Menem.

La economía siguió creciendo con altos índices y ese crecimiento permitió una cierta recomposición positiva de ingresos entre las clases populares. La desocupación fue en el primer trimestre de 2007 de 9,8\%, por debajo del $11,4 \%$ de igual período del 2006 , en medio de un crecimiento del $8,0 \%$ de la economía en estos últimos doce meses, según informes del Instituto Nacional de Estadísticas y Censos. Se canceló la deuda con el FMl y, pese a la sangría que implicó ese pago, las reservas monetarias del país se ubican (en mayo de 2007) en torno a los 40.000 millones de dólares.

En fin, parecen haber vuelto las expectativas positivas, pero ellas no deben hacer olvidar que el proceso electoral dejó en claro que el sistema político argentino estaba en una aguda crisis. Hasta abril de 2003, los principales candidatos eran expresión de la vieja política, la que no termina de morir, mientras la nueva no termina de concebirse (y, por tanto, mucho menos de nacer). De hecho, no existían reglas para regular el consenso y la institucionalización del poder político era una ficción. Sólo la inercia de lo viejo hizo posible mantener un cierto grado de funcionamiento institucional. No obstante, no puede dejar de reconocerse que ha habido un giro importante en el proceso socio-político argentino, siendo temprano aún para saber si él es coyuntural o estratégico.

Ahora bien, el Presidente Néstor Kirchner tiene, como presidente, rasgos que han sido y son clásicos no sólo de un tipo de presidentes, sino de la propia cultura política argentina, en particular la peronista: por ejemplo, los gestos de intolerancia, quizás mejor que autoritarios, amén de un estilo ejecutivo, un claro liderazgo fuerte -históricamente tan al gusto de la mayoría

19 Pero también, como hiciera saber el diario Página 12, la medida apuntó a descabezar a oficiales partidarios de incluir la situación político-militar colombiana como una hipótesis de guerra de los militares argentinos. 
de los argentinos-y una tendencia personalista que, de no mediar acciones colectivas, potencia la también histórica característica de la cultura política argentina de construcciones políticas "desde arriba", que el peronismo, por lo demás, llevó a altas cimas. Dicho de otra manera: la tendencia personalista de líderes fuertes se construye pari passu y en interacción con la simétrica de masas más dispuestas a ser guiadas que a construir una conducción consciente colectiva, es decir, a definir direcciones delegadas, más que personalistas.

Durante su mandato -que concluye en diciembre de este año- se tomaron decisiones tendentes a recuperar cuotas de poder que el Estado había resignado, sin que ellas impliquen un retorno a las intervenciones estatales típicas del Estado de Compromiso Social del pasado, ni tampoco pasibles de ser caracterizadas como nacionalistas. La proclamada intención de hacer de Argentina "un país normal" -para usar la expresión empleada por el presidente en el mensaje ante la Asamblea Legislativa el día de la asunción de su cargo- alude a la recuperación de las instituciones, las del Estado en primer (pero no único) lugar, y por tanto a la restauración del Estado de Derecho. Igualmente es claro que Kirchner impulsa la creación de un nuevo movimiento político, con un cierto tono centro-izquierdista, capaz de recrear el sistema de partidos. ${ }^{20}$ Esa tarea, empero, no será nada fácil: chocará con la oposición de su propio partido, el fracturado Justicialista, y la de quienes, desde fuera del PJ, pretenden ocupar ese espacio tan gelatinoso de la política argentina. Sin contar la obvia oposición de la derecha.

El Presidente ha optado por una estrategia de construcción de poder que, al menos en lo visible, privilegia la relación directa con la opinión pública, prescindiendo de las estructuras partidarias.

Por último, al menos a nuestros efectos, será asimismo relevante lo que haga o deje de hacer Kirchner, como también lo que hagan o dejen de hacer las fuerzas sociales y políticas interesadas en construir, dentro de la matriz estructural existente (toda vez que el cambio de ésta no aparece en el horizonte inmediato con posibilidades de realización), un nuevo modelo nacional, para usar una expresión clásica. ${ }^{21}$

20 Kirchner ha instalado en la opinión pública la incógnita de su sucesión. Como le gusta decir, "será pingüino" o "pinguina". "Pingüinos" es la expresión que se utiliza para designar al Presidente, su esposa - la senadora Cristina Fernández - y otros colaboradores provenientes de la sureña provincia de Santa Cruz, hábitat de dicha ave. Después de concluido este artículo se develó la incógnita: será pinguina, pues la candidata será la senadora Fernández. Kirchner se dedicará a la organización de una nueva fuerza política, de convergencia.

21 Manteniéndome dentro de cánones metodológicos gramscianos, advertiré que la política es expresión de las tendencias de desarrollo de la estructura de la sociedad y, en tanto tales, ellas no tienen porque realizarse necesariamente. Va de suyo que una determinada situación histórica sólo puede aprehenderse de la manera más completa posible sólo después de haberse desarrollado por completo, no mientras transcurre. Pero ello no inhibe la posibilidad de su análisis -incluso historiográfico (historia del tiempo presente), si bien las hipótesis no son susceptibles de verificación empírica en lo inmediato. 


\section{Besuqueos: ¿relegitimación de la representatividad política?}

En el breve lapso de cinco-seis meses, entre abril y setiembre de 2003, el escenario político argentino experimentó una rápida, notable y (para muchos) inesperada transformación. Las radicales consignas del caliente verano 2001-2002 se diluyeron, como también ciertos protagonismos y han mutado, casi, en su antítesis. No se fueron todos, y aunque tampoco se quedaron todos, las bajas han sido contadísimas. Son demasiados los casos de quienes, debiendo haberse ido -según el masivo clamor de los meses más álgidos de la crisis política-, han recuperado, por el voto popular, su continuidad en cargos políticos. Esta relegitimación no es un dato menor en el desarrollo de la crisis.

Simultáneamente, el firme, enérgico liderazgo mostrado por Néstor Kirchner revaloriza la figura presidencial y contribuye a reconstruir la institucionalidad. Ahora bien, la contundencia de las cifras de apoyo al presidente, ratificado por los resultados electorales de setiembre, no es igual a base social y política organizada, a compromiso militante o, al menos, adherente. Un ejemplo: el día de las duras negociaciones con el FMI, en las cuales el presidente mostró firmeza y dignidad, debieron haber habido miles de personas en Plaza de Mayo respaldándolo. En cambio, sólo estuvo un pequeño grupo de piqueteros. La mayoría, en el mejor de los casos, lo vio por televisión o lo siguió por radio.

Los hechos políticos producidos entre diciembre de 2001 y agosto-setiembre de 2003 marcaron un cambio de rumbo. Los mismos son susceptibles de interpretaciones diferentes, aun partiendo de un mismo diagnóstico, según el cual el 19 y el 20 de diciembre constituyeron el momento fundador y la posibilidad de una revolución política, a partir del profundo descontento social. Para algunos, tal posibilidad se agotó, siendo las elecciones de abril su acta de defunción. Las opciones de izquierda han sido neutralizadas y las demandas existentes no se canalizaron por fuera del sistema político, como pareció durante un tiempo, situación que torna posible restablecer los procedimientos institucionales preexistentes para mediar en la resolución de los conflictos. Es decir, el descontento social pudo (y puede ser) canalizado a través de medios políticos, orientándolo hacia la convivencia social.

Para otros, en cambio, la posibilidad de la revolución política se esfumó y redujo a una oportunidad perdida. Se perdió, entre otras razones, por falta de organización, de estrategia, de perspectiva y de un programa político.

No deja de ser significativa una coincidencia entre ambas lecturas, la de concebir la política "como un juego de dos sobre un mismo plano, con homogéneas reglas de juego, como si se tratase de una partida de ajedrez" (como evaluó el Colectivo Situaciones) en la cual se enfrentan el poder, el sistema político, el régimen o el Estado, por un lado, y el poder popular, el contrapoder o la política de la horizontalidad, por el otro. 
La masiva concurrencia a las urnas y el alto voto positivo implicó un duro revés a las posiciones objetoras de las elecciones y también a la izquierda institucional o realmente existente, que pretendió capitalizar electoralmente lo que creyó capacidad de liderazgo de los descontentos y terminó arañando un mísero $3 \%$ de los votos (sumando los de Izquierda Unida y los del Partido O brero). De hecho, tanto el alto nivel de participación electoral cuanto el del voto positivo pueden leerse como una relegitimación del sistema político y de la propia representatividad política, tan fuertemente cuestionada en diciembre de 2001. A la dilución del protagonismo de las asambleas vecinales se sumó la fractura dentro de los movimientos piqueteros, tanto frente a la convocatoria a elecciones, primero, cuanto al nuevo gobierno, después.

Sin embargo, es bueno no olvidar que la realidad es siempre compleja, contradictoria y que por debajo de la superficie fáctico-empírica siempre hay tensiones y dinámicas heterogéneas, no necesariamente visibles. Si ponemos los acontecimientos, los hechos y el proceso en otra perspectiva, no sólo más cuidadosamente atenta y libre de prejuicios sino también temporalmente más extensa, no podemos creer que abril-mayo hayan permitido superar la crisis de representatividad y legitimidad políticas. Diciembre de 2001 [como dice el Colectivo Situaciones, 2003) no fue la antesala de una revolución-ya no social, sino política-, pero si una ruptura, una situación de confrontación entre lo instituido y lo destituyente que no alcanzó a convertirse en un nuevo instituyente. Tampoco fue el surgimiento de un nuevo sujeto político. De allí que éste no se haya manifestado. Lo que sí hubo fue una ruptura y un visible nuevo protagonismo social. "Pero ese protagonismo es lo que es, precisamente, porque no entiende la política como se lo hacía una década atrás". Por eso es inconveniente lamentar (lamento que a veces parece imputación) que esas fuerzas no hayan actuado como si fuesen tal nuevo sujeto. No es buena política ni buena ciencia social adjudicarle a terceros la obligación de efectivizar los deseos del dirigente político o del científico social.

En 2002-2003, el sistema de partidos estaba colapsado. Y aunque las elecciones legislativas y de gobernadores de 2003 mostraron que justicialistas y radicales obtuvieron y se repartieron la mayoría de las gobernaciones y las bancas del Congreso Nacional y de las Legislaturas provinciales, a modo de reproducción (o de remedo) del pasado, si bien en una correlación de fuerzas fuertemente favorable a los primeros, en el escenario nacional no se aprecia una situación similar. En él, tanto unos como otros atraviesan un proceso de disgregación, con notorias tendencias centrífugas, más acentuado en los radicales que en el justicialismo. También la derecha está disgregada. Y la izquierda no cuenta. En pocas palabras, asistimos a una recomposición del sistema de partidos, dentro del cual la centralidad no es la de los viejos partidos sino, como ha señalado hace poco el politólogo Edgardo Mocca, de un sistema de coaliciones que, aunque incluye a esos partidos, se basa más en fuertes liderazgos alternativos. Es posible, 
entonces, imaginar un escenario con fuerzas políticas nuevas constituidas por retazos de otras precedentes.

Porque ha habido ruptura, y por tanto una brecha, cuya magnitud es estructural, no meramente coyuntural, no conviene ilusionarse ni maravillarse con la posibilidad de una relegitimación y una reconstitución automáticas del sistema político, de sus partidos y sus dirigencias por el sólo hecho de masiva presencia de los ciudadanos en las urnas y de su decisión, también abrumadoramente mayoritaria, de votar positivamente. Conviene no obnubilarse por el efecto K, con su estilo ejecutivo y las expectativas abiertas de un cambio de alguna intensidad. Sin negar la posibilidad de convertir estas expectativas en realizaciones, no puede ignorarse que la representatividad política está fuertemente fracturada -como lo mostraron los resultados electorales-y que el piso desde el cual pueden partir las diferentes fuerzas para una nueva construcción es notablemente bajo.

La relegitimación de los políticos -aun si ella sólo fuera parcial y temporaria- y los resultados electorales de 2003 muestran que, en la opción entre el riesgo que implica el cambio y la seguridad que da el orden, la sociedad argentina ha sido fiel a su conservadurismo -sólo esporádicamente alterado- y ha vuelto a ocluir un proceso de transformación. Pero, al mismo tiempo, significativamente, este conservadurismo no se expresó en un retorno al menemismo y sus nuevas variantes, ni, por ahora, en una recomposición orgánica de la derecha, fragmentada en varias expresiones de distinto alcance espacial (lideradas por Ricardo López Murphy, Mauricio Macri, Jorge Sobisch, entre los nombres más relevantes). A su vez, la histórica incapacidad de la izquierda realmente existente para construir una política de poder, incluyendo la más novedosa propuesta de Autodeterminación y Libertad, contribuye al fortalecimiento del conservadurismo. Así, el conservadurismo social de los argentinos no se expresa, hoy, en un correlativo conservadurismo político, sino en uno moderado que, a su vez, no es reacio a tender un puente hacia el gelatinoso espacio del centro-izquierda que pareciera organizarse en una nueva expresión política caracterizada por el, en su momento, llamado transversalismo, impulsado por Kirchner, y que luego se reconfiguró como convergencia pluralista, si bien este proyecto aún no ha adquirido forma orgánica.

Ningún análisis político puede prescindir de lo que ocurre en la sociedad, en la estructura social, en las clases y grupos o sectores que la constituyen. Sin duda, los partidos y agrupaciones políticas existentes no son expresión lineal, o al menos aproximada, de posiciones de clase. Sin embargo, como es frecuente en la historia, la burguesía, el empresariado, el establishment, o como prefieran decirlo los lectores, tiene mayor poder y mayor capacidad para articularse políticamente. Después del derrumbe menemista, los aspirantes a conducir a la derecha argentina -siempre vergonzosa de reconocerse como tal, razón por la cual opta por travestirse de centro-de- 
recha- son varios y han ido cambiando su incidencia y posicionamiento desde abril y setiembre de 2003. El que entonces parecía más sólidamente instalado, Ricardo López Murphy, mantiene capacidad de liderazgo, pero es una incógnita cuánto más puede extender el mismo y captar una base social y/o electoral significativa. A su favor cuenta, en 2007, la situación de sus contendientes. A Mauricio Macri, otro firme candidato al liderazgo de la derecha, la derrota electoral frente a Aníbal Ibarra, en la segunda vuelta porteña en 2003, por la Jefatura de Gobierno de la Ciudad Autónoma de Buenos Aires, no le melló su capital político y su potencial desarrollo. En las elecciones para el mismo cargo en las elecciones de 2007, decidió insistir en dicha postulación, resignando la nacional. ${ }^{22}$ El gobernador de la provincia de Neuquén, Jorge Sobisch, con explícitas pretensiones presidenciales, no vio afectadas sus posibilidades a raíz del asesinato, por la policía de su provincia, de un profesor (Carlos Fuentealba) que participaba de una protesta docente. Pero si los resultados en las elecciones provinciales fueron positivos para su partido, local, el triunfo fue de una corriente interna opuesta. El panorama opositor significativo se completa con la candidatura presidencial -para las elecciones de 2007- de Roberto Lavagna, el ex ministro de Economía de Duhalde y de Kirchner, liderando un espacio de centro, acompañado de la Unión Cívica Radical oficial. ${ }^{23}$

El componente social de la política se hará más evidente aún a la hora de debatir, definir y construir un nuevo modelo nacional. Si éste es el de un capitalismo "serio", nacional y con alguna capacidad, si no de autonomía al menos para negociar con firmeza y dignidad (dentro de los marcos del sistema, como es obvio), es necesario contar -y se trata de una condicio sine qua non- con una burguesía local y con un Estado nacional reconstituido, aun cuando no alcance los contenidos que tuvo hasta la crisis de 1975. Y aquí está el nudo de la cuestión, pues la burguesía local o nacional argentina dista de ser -como lo prueba la historia- un sujeto social confiable para un proyecto estratégico como el que parece imaginar el presidente. Y si lo fuese, ha de necesitar su contradictor, organizado social y políticamente. En la fase actual del capitalismo argentino, tal contradictor ha de incluir a proletarios, trabajadores, empleados, científicos, técnicos, intelectuales y otros sectores de clase media. No obstante, hasta ahora, de eso no se habla.

Empero, no hay que confundirse: haber pasado de los mandobles a los besuqueos, en poco tiempo, es, sin dudas, un dato relevante. Pero el besuqueo no es necesariamente amor.

22 Macri ganó en primera vuelta con casi $46 \%$ de los votos emitidos. En la segunda vuelta -el 24 de junio, después de concluido este artículo - se enfrentó con Daniel Filmus, actual Ministro de Educación de la Nación (quien había obtenido casi $26 \%$ ). El candidato derechista aumento su caudal al $61 \%$.

23 A falta de una mejor, uso esta expresión para referirme a la UCR histórica, dentro de la cual se encuentra el ex presidente Alfonsín, y diferenciarla de los llamados radic ales K, dirigentes, gobernadores e intendentes (prefectos) de origen radical, ahora enrolados con Kirchner. Es posible que uno de ellos sea candidato a Vicepresidente. 